\title{
FormaÇão de RAízes EM ESTACAS de dUAS ESPÉCIES de CALLIANDRA (Leguminosae - Mimosoideae)
}

\author{
Juliana Lischka Sampaio Mayer ${ }^{1}$, Nerio Aparecido Cardoso ${ }^{2}$, \\ Francine Cuquel ${ }^{2}$ \& Cleusa Bona ${ }^{1,3}$
}

\begin{abstract}
RESUMO
(Formação de raízes em estacas de duas espécies de Calliandra (Leguminosae - Mimosoideae)) Calliandra brevipes e Calliandra tweedii, também conhecidas como caliandra ou esponjinha, são espécies nativas do Brasil cultivadas como plantas ornamentais. O objetivo deste trabalho foi avaliar os efeitos da aplicação de diferentes concentrações de ácido Indolbutírico (AIB) no enraizamento de Calliandra tweedii e Calliandra brevipes e relacioná-los com a estrutura anatômica das estacas. Ambas as espécies apresentaram um aumento na porcentagem de enraizamento e no número de raízes quando tratadas com AIB. Todos os tratamentos de Calliandra brevipes obtiveram porcentagens de enraizamento superiores às de Calliandra tweedii, sendo que os melhores resultados desta foram com $2000 \mathrm{mg} . \mathrm{L}^{-1} \mathrm{AIB}$ (56,67\%). C. brevipes teve $90 \%$ de enraizamento sem a necessidade de aplicação de AIB. A raiz tem origem direta em ambas as espécies, podendo originar-se na região interna ou externa do floema. Provavelmente, os fatores limitantes ao enraizamento de $C$. tweedii são devidos à estrutura anatômica e físiológica, como a ausência de grânulos de amido na região da medula. Palavras-chave: estaquia, análise anatômica, propagação vegetativa, plantas ornamentais, caliandra.
\end{abstract}

\begin{abstract}
(Root formation in cuttings of two species of Calliandra (Leguminosae - Mimosoideae)) Calliandra brevipes and Calliandra tweedii, known as 'caliandra' or 'esponjinha', are native Brazilian ornamental species. This experiment aimed to evaluate the effect of the application of different concentrations of Indolbutiric acid (IBA) in root formation of both species by observing anatomical structure. Both species presented an increase in root formation percentage and number of new roots when treated with IBA. All Calliandra brevipes treatments achieved higher root formation percentages than Calliandra tweedii. The best results of C. brevipes were $2000 \mathrm{mg} . \mathrm{L}^{-1} \mathrm{IBA}(56,67 \%)$. C. brevipes had $90 \%$ of rooting without IBA application. Roots originated directly for both species, either from the inner or outer phloem region. Probably the limiting factors for $C$. tweedii root formation were linked to its anatomy and physiology, such as the absence of starch granules in the medular region.
\end{abstract}

Key words: plant cuttings, plant anatomy, vegetative propagation, ornamental plants, caliandra.

\section{INTRODUÇÃo}

Calliandra brevipes Benth. e Calliandra tweedii Benth. são espécies nativas do Brasil, pertencentes à família Leguminosae (Mimosoideae) e apresentam florescimento exuberante rosa e vermelho, respectivamente. Essas espécies são utilizadas como plantas ornamentais isoladas ou como cerca-viva (Lorenzi \& Souza 2001; Paiva 2003).

A propagação vegetativa ou clonal é o método mais utilizado na produção comercial de diversas culturas ornamentais e frutíferas tendo como vantagens a reprodução de todas as características da planta matriz, a uniformidade e qualidade na produção (Hartmann et al. 2002). Além disso, reduz o período improdutivo, antecipando a floração quando comparada aos indivíduos propagados via sementes (Casagrande et al. 2000). São escassos os trabalhos de propagação vegetativa utilizando espécies ornamentais nativas do Brasil. A produção comercial de flores e plantas, que de início se encontrava restrita a alguns países europeus e ao Japão, tem se expandido para várias regiões do mundo, principalmente devido à necessidade

Artigo recebido em 07/2007. Aceito para publicação em 06/2008.

${ }^{1}$ Departamento de Botânica, Setor de Ciências Biológicas, Universidade Federal do Paraná, Centro Politécnico, Jardim das Américas, C.P. 19031, 81531-970, Curitiba, PR, Brasil.

${ }^{2}$ Universidade Federal do Paraná, Setor de Ciências Agrárias, Dept. Fitossanitarismo, 80035-050, Curitiba, PR, Brasil.

${ }^{3}$ Autor para correspondência: cleusabona@ufpr.br 
de redução dos custos produtivos e de disponibilidade de mão-de-obra (Leitão 2003).

A estaquia é um dos métodos de propagação vegetativa mais utilizados e apresenta como ponto crítico o início do desenvolvimento de um sistema radicular funcional (Thomas \& Schiefelbein 2002). A formação de raízes adventícias pode ser considerada como uma seqüência de eventos bioquímicos e histológicos (Moreira et al. 2000). É um evento multicelular complexo, envolvendo a divisão celular em células que normalmente não estão diretamente relacionadas na formação raízes. Tanto em plantas arbóreas como em herbáceas ocorrem dois modos distintos de formação de raízes adventícias. O primeiro, é denominado de desenvolvimento direto, no qual o primórdio radicular tem origem de células do sistema vascular ou de células próximas a ele. O segundo, é o desenvolvimento indireto, no qual ocorre a proliferação de um tecido indiferenciado, chamado de calo, antes da formação do primórdio radicular (Altamura 1996).

Alguns autores identificaram relação entre a estrutura do caule e a capacidade de formar raízes adventícias. Beackbane (1961) cita que a presença de uma camada contínua de fibras ao redor do floema secundário inibe a formação de raízes adventícias em Pyrus sp. Estacas com concentrações mais elevadas de carboidratos, normalmente, apresentam melhores taxas de enraizamento (Hartmann et al. 2002), pois segundo Hess (1969) os carboidratos são a fonte de energia para a síntese de outras substâncias essenciais para a formação das raízes adventícias. Outro fator importante é a presença de compostos fenólicos na estaca, o qual pode estimular ou inibir a formação de raízes (Bartolini et al. 1991), sendo que o enraizamento pode ser estimulado pela presença de monofenóis e inibido por polifenóis (Ono \& Rodrigues 1996).

A aplicação exógena de auxinas em estacas estimula a formação de raízes adventícias, aumentando a porcentagem de estacas enraizadas, o número de raízes formadas e a uniformidade do enraizamento (Hartmann et al. 2002; Taiz \& Zeiger 2004).
O ácido indol butírico (AIB) é um dos reguladores vegetais mais utilizados devido a sua baixa mobilidade, maior estabilidade química e em concentrações adequadas, as quais dependem de cada espécie, não é fitotóxico (Audus 1963). Segundo De Klerk et al. (1990), as auxinas são requeridas nas fases inicias da formação das raízes, porém elas podem inibir o subseqüente crescimento e desenvolvimento do primórdio radicular.

O presente estudo, teve como objetivo testar a influência da aplicação de AIB sobre o processo de enraizamento de $C$. brevipes e C. tweedii, utilizando diferentes concentrações do fitorregulador ácido indol butírico e verificar se a porcentagem de enraizamento tem relação com a estrutura anatômica das estacas.

\section{Material e Métodos}

$\mathrm{O}$ experimento foi conduzido em casade-vegetação no Setor de Ciências Agrárias da UFPR (Universidade Federal do Paraná), de março a maio de 2005.

O material vegetal foi obtido a partir de plantas situadas no Setor de Ciências Agrárias da UFPR, Curitiba-PR, latitude 25 24'46" e longitude $49^{\circ} 14^{\prime} 52$ ". O comprimento das estacas foi de $15 \mathrm{~cm}$, com duas folhas reduzidas a metade, e as bases cortadas em bisel. Os tratamentos com o fitorregulador ácido indol butírico (AIB), foram: 0 (testemunha), 500, $1.000,1.500$ e $2.000 \mathrm{mg} . \mathrm{L}^{-1}$ AIB, as regiões basais das estacas foram mergulhadas na solução alcoólica 50\% durante 10 segundos.

As estacas foram plantadas em tubetes preenchidos com o substrato vermiculita de granulometria média em casa-de-vegetação com nebulização intermitente (das 8:00 às 17:0015 segundos a cada 15 minutos; das 17:00 às 22:00-15 segundos a cada 60 minutos, e das 22:00 às 08:00-15 segundos a cada 180 minutos). As condições mínimas e máximas de temperatura e umidade da casa-de-vegetação foram 13,5$27^{\circ} \mathrm{C}$ e $54-99 \%$, respectivamente.

Após 65 dias do plantio, foram avaliados o número de raízes por estaca, a porcentagem de estacas vivas enraizadas, estacas com calos 
e estacas mortas. O delineamento experimental foi inteiramente casualizado, num esquema fatorial 2 por 5 ( 2 espécies e 5 concentrações de fitorregulador), com três repetições por tratamento e 10 estacas por parcela, totalizando 150 estacas por espécie. Os dados obtidos foram analisados pelo teste de Bartlett para verificar se as variâncias dos tratamentos foram homogêneas. Posteriormente, foi efetuada a análise de variância e a comparação entre as médias dos tratamentos pelo teste de Tukey.

Para a análise anatômica qualitativa foram coletadas amostras da base das estacas de todos os tratamentos após 65 dias da instalação do experimento, as quais foram fixadas em F.A.A. 70 (álcool 70\%, ácido acético e formaldeido, 90:5:5) (Johansen 1940) e posteriormente conservadas em álcool $70 \%$. Os materiais destinados à preparação de lâminas permanentes foram incluídos em meta-acrilato-glicol (historesina), segundo a técnica de Feder \& O'Brien (1968) e as indicações do fabricante. Os blocos foram seccionados em micrótomo de rotação, e os cortes foram obtidos com $8 \mathrm{~mm}$ de espessura e corados com azul de toluidina (Feder \& O'Brien 1968). As lâminas foram montadas com resina sintética (permount). Foram realizados testes microquímicos, com lugol e cloreto férrico (Johansen 1940) a partir do material seccionado em micrótomo, com montagem semipermanente.

\section{Resultados}

As estacas de Calliandra brevipes apresentam periderme e seis a sete camadas de parênquima cortical com células de conteúdo denso. O cilindro vascular é circundado por grupos de fibras pericíclicas. Essas fibras formam calotas mais espessas em posição oposta ao floema primário. O cilindro vascular encontra-se em crescimento secundário com câmbio vascular ativo, formando várias camadas de células derivadas (Fig. 1a e 1c). Células com conteúdo denso na região da medula e do córtex responderam ao teste com cloreto férrico, evidenciando a presença de compostos fenólicos hidrofílicos.

As estacas de Calliandra tweedii, da mesma forma que em $C$. brevipes, possuem periderme, córtex parenquimático e medula com células de conteúdo denso. Porém, as fibras pericíclicas formam uma faixa contínua ao redor do cilindro vascular, sendo mais larga e regular do que em C. brevipes. Em Calliandra tweedii as fibras apresentam parede celular mais espessada, crescimento secundário mais avançado e faixa cambial mais estreita que em C. brevipes (Fig. 1b e 1d).

Calliandra tweedii aos 65 dias da instalação do experimento, apresentou $100 \%$ de estacas com calos para todos os tratamentos e $56,67 \%$ de estacas vivas enraizadas (Fig. 2). Essas estacas desenvolveram calos esbranquiçados e de aspecto compacto na base. Os calos (massa de tecido parenquimático) se originam internamente às fibras pericíclicas e empurram o córtex e a periderme para fora à medida que crescem (Fig. 1e). Com o desenvolvimento desse tecido, a camada de fibras se rompe. $\mathrm{O}$ cilindro vascular permanece intacto, no entanto alguns elementos de vaso ficam com o lume obstruído (Fig. 1e e 1f). A obstrução dos elementos de vaso também foi registrada em $C$. brevipes, porém, esta espécie não apresentou estacas mortas (Fig. 3) nem formou calos.

A raiz tem origem direta em ambas as espécies, portanto o desenvolvimento dessas foi diretamente de células da região externa do floema junto ao periciclo ou da região interna do floema secundário próximo ao câmbio (Fig. 1f e 4a). Mesmo ocorrendo a formação de calos em C. tweedii, não foi identificada a formação de meristemóides nesses tecidos. As raízes formadas em ambas as espécies fazem conexão vascular com o caule, preferencialmente, na posição do raio vascular (Fig. 4b-d).

$\mathrm{O}$ teste com lugol evidenciou a presença de amido na medula do caule de $C$. brevipes (Fig. 4e), ao contrário do observado em $C$. tweedii (Fig. 4f), na qual não foi observada a presença de amido na medula. Já o teste com 


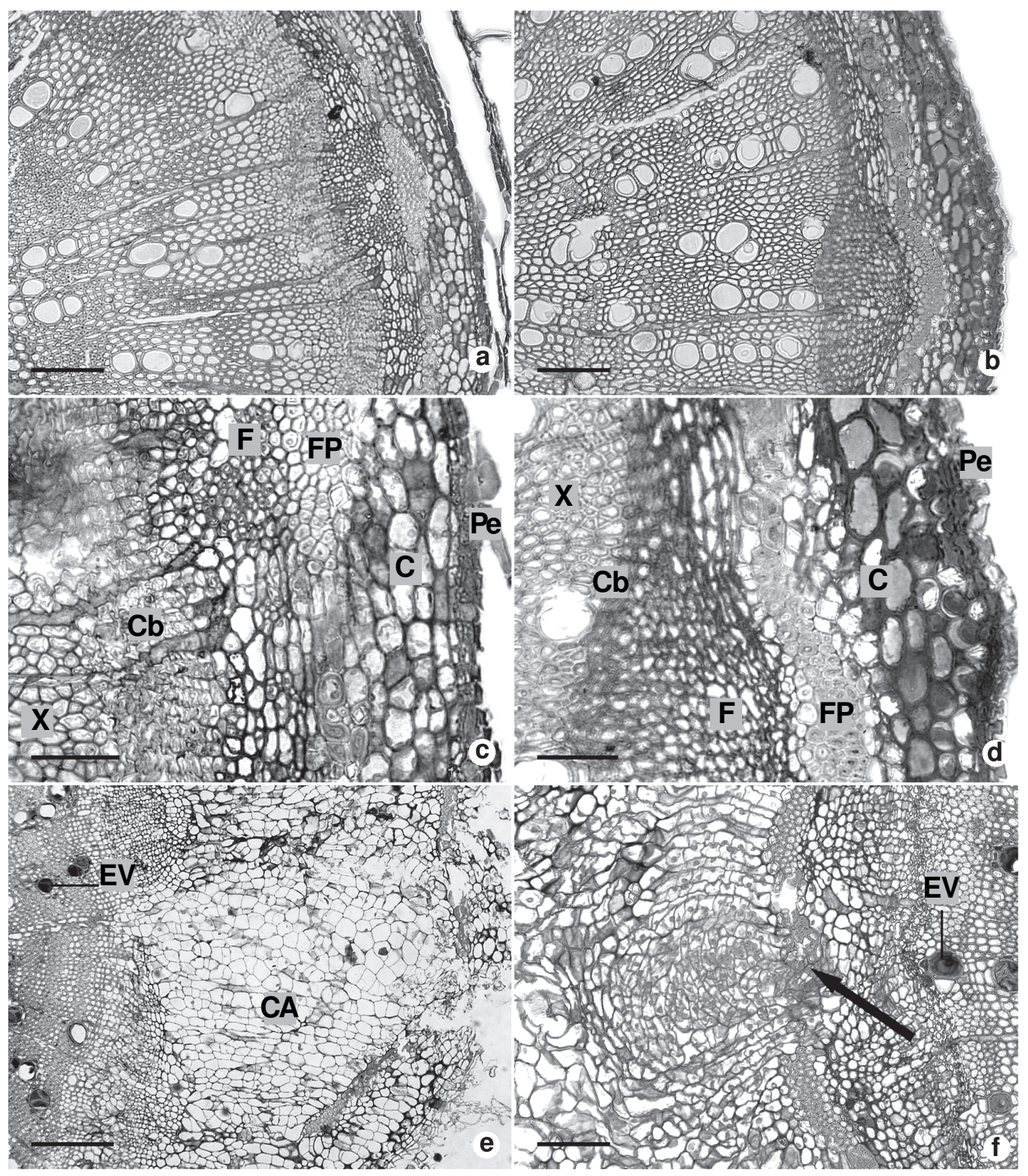

Figura 1 - Secções transversais de estacas caulinares de duas espécies de Calliandra - a, c. vista geral e detalhe de C. brevipes no dia 0 da instalação do experimento; $\mathrm{b}$, d. vista geral e detalhe de $C$. tweedii no dia 0 da instalação do experimento; e-f. no $65^{\circ}$ dia após a instalação do experimento: e. C. tweedii com calo evidente devido a proliferação celular internamente as fibras pericíclicas; f. $C$. tweedii, início do desenvolvimento do primórdio radicular com origem provavelmente da região externa do floema junto ao periciclo nas regiões onde não ocorreu a proliferação de calo. $(\mathrm{C}=$ córtex; $\mathrm{CA}=$ calo; $\mathrm{Cb}=$ câmbio; $\mathrm{EV}=$ elementos de vaso obliterados; $\mathrm{F}=$ floema; $\mathrm{FP}=$ fibras periciclicas; $\mathrm{Pe}=$ periderme; $\mathrm{X}=$ xilema secundário $)$. Barra $=100 \mu \mathrm{m}(\mathrm{a}, \mathrm{b}, \mathrm{f}) ; 50 \mu \mathrm{m}(\mathrm{c}-\mathrm{d}) ; 200 \mu \mathrm{m}(\mathrm{e})$. 
cloreto férrico revelou a presença de compostos fenólicos hidrofílicos na região da medula e córtex de ambas as espécies.

C. brevipes apresentou valores significativamente superiores para as variáveis porcentagem de estacas enraizadas (Fig. 2) e número de raízes por estacas (Fig. 5) e valores inferiores para a variável porcentagem de estacas mortas (Fig. 3). Esses resultados demonstram a eficiência de enraizamento dessa espécie em relação a $C$. tweedii.

\section{Discussão}

Segundo Esaú (1976), raízes adventícias são encontradas em todas as plantas vasculares em partes aéreas, como folhas e caules, caules subterrâneos e em regiões da própria raiz. A formação de raízes em partes aéreas das plantas é importante para a propagação vegetativa e geralmente tem origem endógena. Como o observado em ambas as espécies de Calliandra, nas quais a origem das raízes adventícias foi direta nos tratamentos com ou sem a aplicação de AIB. Diferindo do observado por Moreira et al. (2000), os quais verificaram que a aplicação exógena de AIB altera a origem das raízes adventícias em Gomphrena macrocephala A. St.-Hil., sem a aplicação do fitorregulador a origem das raízes era direta pela divisão celular no periciclo. Com a aplicação do fitorregulador a origem das raízes passa a ser tanto direta como indireta. A origem indireta é observada pelo surgimento de meristemóides na periferia de calos, as raízes originadas dessa forma não formam conexão vascular com o caule. Ainda para Gomphrena macrocephala, a presença de calos só foi observada em microestacas com a aplicação de AIB. Essa modificação na origem da raiz adventícia também foi observada por De Klerk et al. (1990) em microestacas de maça.

A presença do desenvolvimento de calos em $C$. tweedii parece ser um pré-requisito para a formação de raízes adventícias e a aplicação exógena de $2000 \mathrm{mg} . \mathrm{L}^{-1}$ de AIB aumenta a porcentagem de estacas enraizadas (Fig. 2).

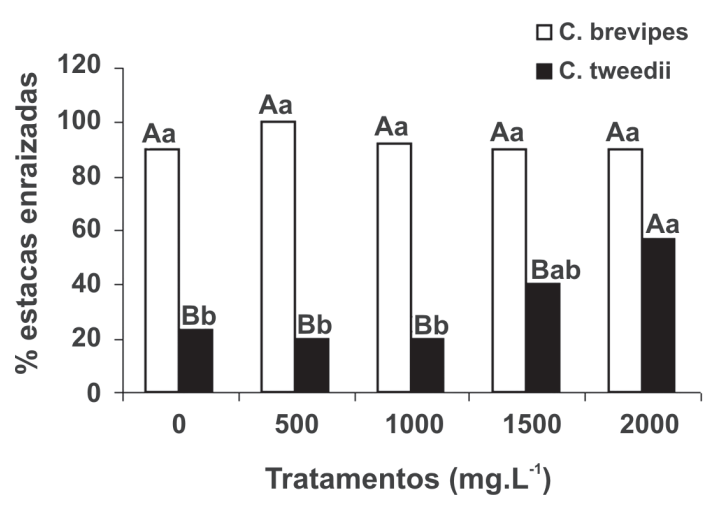

Figura 2 - Porcentagem de estacas vivas enraizadas de C. brevipes e C. tweedii, nos diferentes tratamentos com o fitorregulador AIB, no $65^{\circ}$ dia após a instalação do experimento. Médias seguidas pela mesma letra minúscula não diferem estatisticamente para as concentrações de AIB e as letras maiúsculas para a comparação entre espécies ao nível de $95 \%$.

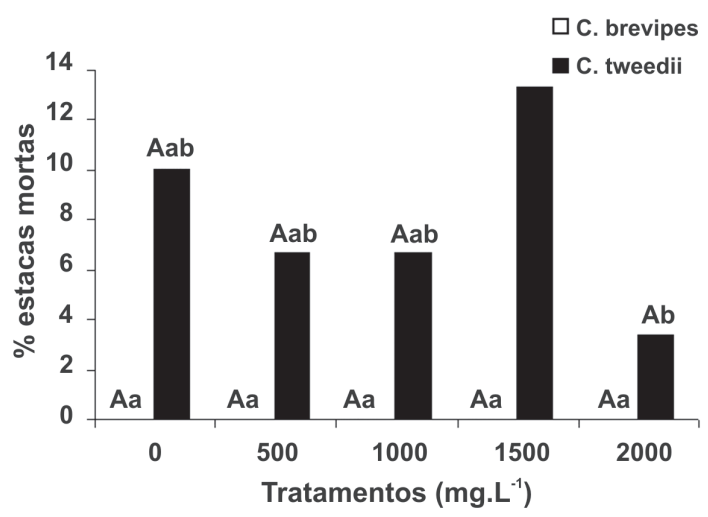

Figura 3 - Porcentagem de estacas mortas de $C$. brevipes e C. tweedii, nos diferentes tratamentos com o fitorregulador $\mathrm{AIB}$, no $65^{\circ}$ dia após a instalação do experimento. Médias seguidas pela mesma letra minúscula não diferem estatisticamente para as concentrações de AIB e as letras maiúsculas para a comparação entre espécies ao nível de $95 \%$.

Segundo Taiz \& Zeiger (2004) a auxina estimula as células do periciclo a se dividirem e, gradualmente, formam o primórdio radicular. Schwarz et al. (1999) verificaram que as raízes adventícias de Acacia baileyana F. Muell. surgem de calos adjacentes ao parênquima do floema. A conexão vascular dessas raízes é estabelecida pela proliferação do raio. Segundo os autores, essa espécie apresenta calos em todos os tratamentos e raízes só foram observadas em estacas com calos.

A origem direta das raízes, em ambas as espécies de Calliandra, surgindo da região 

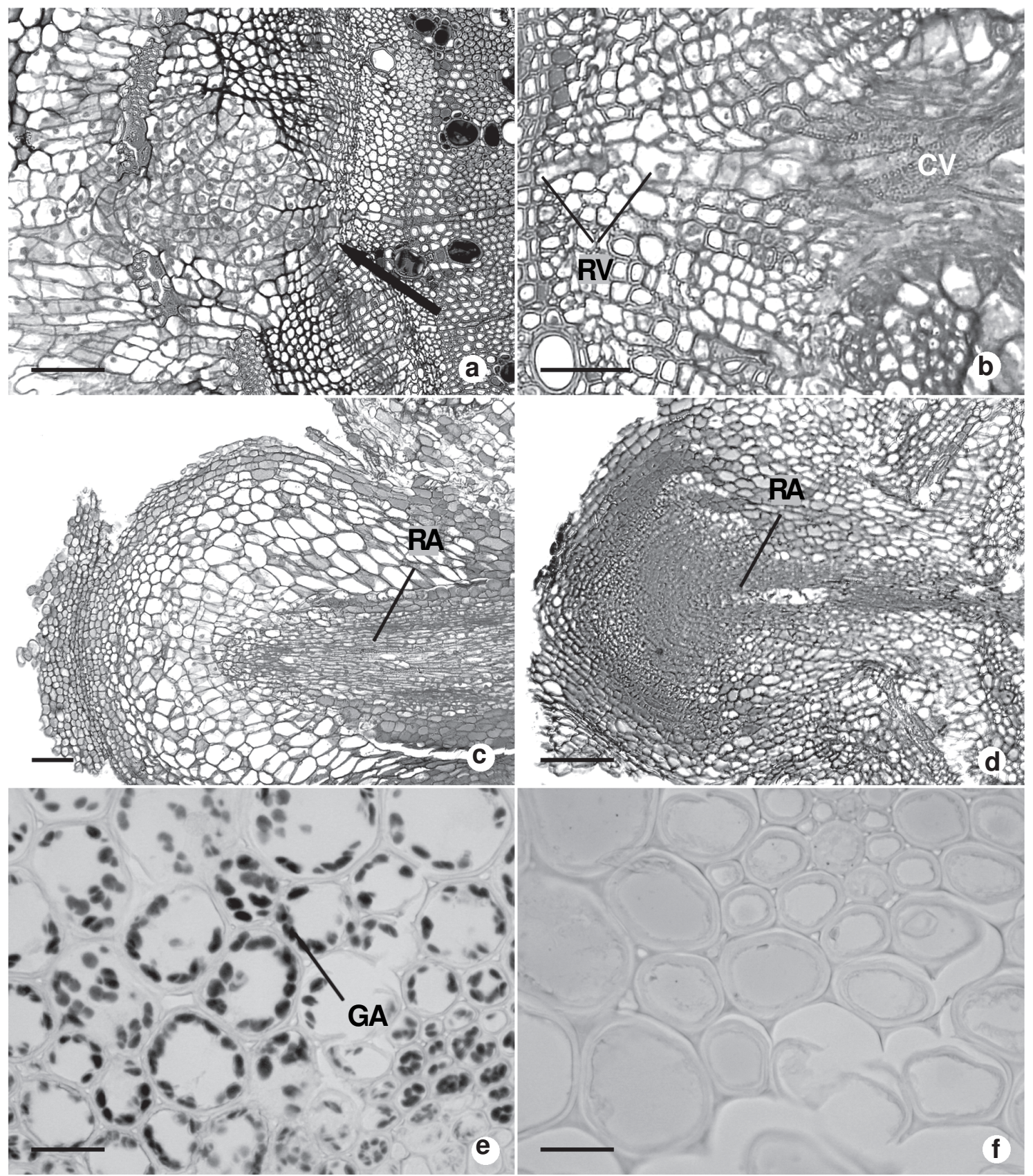

Figura 4 - Secções transversais de estacas caulinares de duas espécies de Calliandra no $65^{\circ}$ dia após a instalação do experimento. a. Calliandra tweedii, início do desenvolvimento do primórdio radicular com origem da região interna do floema secundário próximo ao câmbio (seta); b. C. brevipes evidenciando a conexão vascular com a raiz adventícia; c. C. tweedii, emergência da raiz adventícia; d. C. brevipes, emergência da raiz adventícia; e. C. brevipes, teste com lugol evidenciando grânulos de amido na medula; f. $C$. tweedii, teste com lugol revelando a ausência de amido. (CV = conexão vascular; $\mathrm{GA}=$ grânulos de amido; $\mathrm{RA}=$ raiz adventícia; $\mathrm{RV}=$ raio vascular). $\mathrm{Barra}=100 \mu \mathrm{m}(\mathrm{a}, \mathrm{c}-\mathrm{f}) ; 50 \mu \mathrm{m}(\mathrm{v})$. 
externa do floema junto ao periciclo ou da região interna do floema secundário próximo ao câmbio também foi registrada para outras espécies. Hilaire et al. (1996) observaram que a origem das raízes adventícias em Mussaenda erythrophylla Schumach. \& Thonn. ocorre a partir de células do parênquima do floema próximas à região do câmbio vascular. Os autores afirmam que isto indica a capacidade das células do parênquima do floema se desdiferenciarem e tornarem-se meristemáticas. No entanto, outros autores citam a origem da raiz a partir do câmbio vascular como registrado para o caqui japonês, Diospyros kaki Thunb. (Tetsumura et al. 2001), e para castanheira-da-índia, Castanea sativa Mill. (Vieitez et al. 1980).

A aplicação exógena de AIB não influenciou a porcentagem de enraizamento de C. brevipes (Fig. 2). Ao contrário do observado em $C$. tweedii, na qual a aplicação de 2000 mg.L $\mathrm{L}^{-1}$ de AIB elevou significativamente a porcentagem de enraizamento em relação à testemunha, respectivamente de $23,33 \%$ para $56,67 \%$ (Fig. 2). Portanto, um dos possíveis fatores limitantes ao enraizamento nessa espécie é a concentração de auxina. Pois segundo Hartmann et al. (2002), para que ocorra a formação de raízes adventícias em estacas é necessária a presença de auxinas, de co-fatores, como o boro, de carboidratos e a ausência de substâncias inibidoras.

O número de raízes em $C$. brevipes foi mais elevado com a aplicação do fitorregulador, porém em $C$. tweedii somente com a aplicação de $1.000 \mathrm{mg} . \mathrm{L}^{-1} \mathrm{o}$ resultado foi superior a testemunha (Fig. 5). Carvalho-Oliveira et al. (2003) não obtiveram estacas enraizadas de C. tweedii nos tratamentos com AIB nas formas de solução e talco nas concentrações de 0 , 1.000 e $2.000 \mathrm{mg} . \mathrm{L}^{-1}$ e com substrato casca de arroz carbonizada. Já Lima et al. (2006), obteviveram $13,33 \%$ das estacas de C. tweedii enraizadas utilizando $1500 \mathrm{mg} . \mathrm{L}^{-1}$ de ácido naftaleno acético (ANA). Estes últimos autores, estudando a capacidade de enraizamento de C. tweedii e de Calliandra selloi J.F. Macbr., também verificaram a baixa capacidade de

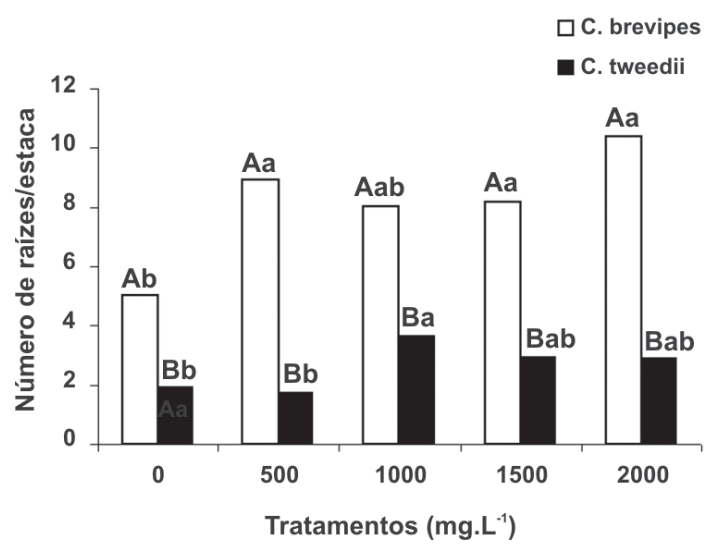

Figura 5 - Número de raízes por estaca de $C$. brevipes e C. tweedii, nos diferentes tratamentos com o fitorregulador $\mathrm{AIB}$, no $65^{\circ}$ dia após a instalação do experimento. Médias seguidas pela mesma letra minúscula não diferem estatisticamente para as concentrações de AIB e as letras maiúsculas para a comparação entre espécies ao nível de $95 \%$.

C. tweedii $(6,67 \%)$ em relação a $C$. selloi $(96,67)$ sem a aplicação de fitorregulador. Os autores ainda citam que é evidente que o desenvolvimento do sistema radicular está diretamente relacionado à capacidade de cada espécie.

A dificuldade de enraizamento de $C$. tweedii em relação a $C$. brevipes, pode ser atribuída à camada contínua de fibras pericíclicas, uma vez que em $C$. brevipes essa camada é descontínua. Concordando, com o observado por Beakbane (1961), que as plantas com dificuldade de enraizamento, normalmente, apresentam fibras esclerenquimáticas próximas ao floema primário. Ono \& Rodrigues (1996) e Paiva \& Gomes (1993) também verificaram que a diferença entre variedades de fácil ou difícil enraizamento pode estar inversamente relacionada com a continuidade da camada de esclerênquima. Mayer et al. (2006), relacionou a baixa capacidade de enraizamento de Vitis rotundifolia Michx. cv. Topsail às características anatômicas deste cultivar: como a presença de calotas de fibras do floema primário; floema secundário reduzido com faixas radiais de fibras envolvendo o parênquima axial e os elementos condutores; raios estreitos e a maior concentração de compostos fenólicos, principalmente no raio. 
A presença de amido também pode ter influenciado a formação de raízes, já que $C$. brevipes armazena grânulos de amido na medula (Fig. 4e), ao contrário do observado em C. tweedii (Fig. 4f). Concordando com a afirmação de Hess (1969), na qual a presença de carboidratos é essencial para a formação das raízes adventícias. Além disso, Paiva \& Gomes (1993) e Hartmann et al. (2002) também afirmam que para uma elevada taxa de enraizamento é necessário um alto teor de carboidratos e um baixo teor de nitrogênio na planta matriz.

O teste microquímico com cloreto férrico revelou a presença de compostos fenólicos em ambas às espécies de forma semelhante. Portanto, esses compostos não devem ter sido o fator limitante à formação de raiz. No entanto, de acordo com Bartolini et al. (1991) e Ono \& Rodrigues (1996), os compostos fenólicos podem tanto estimular como inibir a formação da raiz na estaca. Sendo assim, seria necessário definir se os compostos observados são monofenóis ou polifenóis.

Com base nos dados obtidos conclui-se que o AIB não influenciou o enraizamento de $C$. brevipes, ao contrário de $C$. tweedii, na qual elevou-se a porcentagem de enraizamento em relação à testemunha com a aplicação exógena de $2000 \mathrm{mg} . \mathrm{L}^{-1}$ de AIB. Nesta última espécie, a baixa porcentagem de enraizamento observada em condições experimentais, pode estar associada à presença da camada contínua de fibras pericíclicas e a ausência de armazenamento de amido.

\section{REFERÊNCIAS BIBLIOGRÁFICAS}

Altamura, M. M. 1996. Root histogenesis in herbaceous and woody explants cultured in vitro. A critical review. Agronomie 16: 589-602.

Audus, L. J. 1963. Plant growth substances. 2. ed. Intersciences, New York.

Bartolini, G.; Taponi, M. A. \& Santini, L. 1991. Propagation by cuttings of 2 Vitis rootstocks - diffusion of endogenous phenolic compounds into the dipping waters. Journal of Experimental Botany 52: 9-15.
Beackbane, A. B. 1961. Structure of the plant stem in relation to adventitious rooting. Nature 192: 954-955.

Casagrande, J. G Jr.; Dutra, F. L.; Tonietto, A.; Nachtigal, J. C. \& Strelow, E. 2000. Efeito do estiolamento de ramos e do AIB no enraizamento de estacas herbáceas de jabuticabeira. Revista Brasileira de Agrociência 6(1): 24-26.

Carvalho-Oliveira, M. M. C.; Alcantara, G. B.; Cunha, M. R.; Denega, S. \& ZuffellatoRibas, K. C. 2003. Efeito do ácido indol butiríco (IBA) no enraizamento de estacas caulinares de Calliandra tweedii BENTH. In: IX Congresso Brasileiro de Fisiologia Vegetal. Atibaia-SP, 242p.

De Klerk, G. J.; Keppel, M.; Ter Brugge, J. \& Meekes, H. 1990. Timing of the phases in adventitious root formation in apple microcuttings. Journal of Experimental Botany 46: 965-972.

Esau, K. 1976. Anatomy of seed plants. $3^{\text {th }}$ ed. John Willey and Sons, New York.

Feder, N. \& O'Brien. T. P. 1968. Plant microtechnique: some principles and new methods. American Journal of Botany 55(1): 123-142.

Hartmann, H. T.; Kester, D. E. 2002. Plant propagation: principles and pratices. $7^{\text {th }} \mathrm{ed}$. Prentice Hall, New Jersey, 880p.

Hess, C. E. 1969. Internal and external factors regulating root initiation; root growth. Buttersworth, London.

Hilaire, R. St.; Berwart, C. A. F. \& PérezMuñoz, C. A. 1996. Adventitious root formation and development in cuttings of Mussaenda erythrophylla L. Schum. \& Thonn. HortScience 31(6): 1023-1025.

Johansen, D. A. 1940. Plant microtechnique. MacGraw, New York.

Lima, D. M.; Alcantara, G. B.; Bortolini, Fanti, F. P.; Biasi, L. A.; Quoirin, M.; Koehler, H. S. \& Zuffellato-Ribas, K. C. 2006. Substratos e concentrações de ácido naftaleno acético no enraizamento de estacas semilenhosas de Calliandra selloi e Calliandra tweediei. Scientia Agraria 7: 105-111. 
Leitão, A. P. S. 2003. O mercado de flores e plantas ornamentais (Palestra ministrada). In: XIV Congresso Brasileiro de Floricultura e Plantas Ornamentais, I Congresso Brasileiro de Cultura de Tecidos de Plantas. Lavras-MG.Pp.2-5.

Lorenzi, H. \& Souza H. M. 2001. Plantas ornamentais no Brasil - Arbustivas, herbáceas e trepadeiras. 3 ed. Plantarum, Nova Odessa, 1088p.

Mayer, J. L. S.; Biasi, L. A. \& Bona, C. 2006. Capacidade de enraizamento de estacas de quatro cultivares de Vitis L. (Vitaceae) relacionada com os aspectos anatômicos. Acta Botânica Brasilica 20(3): 563-568.

Moreira, F. M.; Appezzato-da-Glória, B. \& Zaidan, L. B. P. 2000. Anatomical aspects of IBA-treated microcuttings of Gomphrena macrocephala St.-Hil. Brasilian Archives of Biology and Technology 43(2): 221-227.

Ono, E. O. \& Rodrigues, J. D. 1996. Aspectos da fisiologia do enraizamento de estacas caulinares. Jaboticabal, FUNEP.

Paiva, P. D. O. 2003. Características das principais plantas ornamentais utilizadas em paisagismo. Editora UFLA, Lavras.
Paiva, H. N. \& Gomes, J. M. 1993. Propagação vegetativa de espécies florestais. UFV, Viçosa.

Schwarz, L. J.; Glocke, P. L. \& Sedgley, M. 1999. Adventitious root formation in Acácia baileyana F. Muell. Journal of Horticultural Science \& Biotechnology 74(5): 561-565.

Taiz, L. \& Zeiger, E. 2004. Fisiologia Vegetal. 3 ed. Artmed, Porto Alegre.

Tetsumura, T.; Tao, R. \& Sugiura, A. 2001. Some factors affecting the rooting of softwood cuttings of Japanese persimmon. Journal of the Japanese Society of Horticultural Science 70(3): 275-280.

Thomas, P. \& Schiefelbein, J. 2002. Cloning and characterization of an actin depolymerizing factor gene from grape (Vitis vinifera L.) expressed during rooting in stem cuttings. Plant Science 162: 283-288.

Vieitez, A. M.; Ballester, A.; Garcia, M. T. \& Vieitez E. 1980. Starch depletion and anatomical changes during the rooting of Castanea sativa Mill. Scientia Horticulturae 13: 261-266. 